\title{
Synthesis and Biological Evaluation of 2-and 3-Amino Benzo[b]Thiophene Derivatives as Antimitotic Agents and Inhibitors of Tubulin Polymerization
}

Romeo Romagnoli*†, Pier Giovanni Baraldi*†, Maria Dora Carrion ${ }^{\dagger}$, Carlota Lopez Cara ${ }^{\dagger}$, Delia Preti ${ }^{\dagger}$, Francesca Fruttarolo ${ }^{\dagger}$, Maria Giovanna Pavani ${ }^{\dagger}$, Mojgan Aghazadeh Tabrizi ${ }^{\dagger}$, Manlio Tolomeo ${ }^{\dagger \dagger}$, Stefania Grimaudo ${ }^{\dagger \dagger}$, Antonella Di Cristina ${ }^{\dagger \dagger}$, Jan Balzarini ${ }^{\Psi}$, John A. Hadfield $^{\S}$, Andrea Brancale ${ }^{\S \S}$ and Ernest Hamel ${ }^{\ddagger}$

Dipartimento di Scienze Farmaceutiche, Università di Ferrara, 44100 Ferrara, Italy; Divisione di Ematologia e Servizio AIDS, Dipartimento di Oncologia, Policlinico "P. Giaccone”, Università di Palermo, Palermo, Italy; Rega Institute for Medical Research, Laboratory of Virology and Chemotherapy, Minderbroedersstraat 10, B-3000 Leuven, Belgium; Centre for Molecular Drug Design, Cockroft Building, University of Salford, Manchester, M5 4W5, UK; The Welsh School of Pharmacy, Cardiff University, King Edward VII Avenue, Cardiff, CF10 3XF, UK; Toxicology and Pharmacology Branch, Developmental Therapeutics Program, Division of Cancer Treatment and Diagnosis, National Cancer Institute at Frederick, National Institutes of Health, Frederick, Maryland 21702, USA

\section{SUPPORTING INFORMATION}

Characterization of compounds 6a-e,7a-l, 9a-e, 10a-e, 11a-e, 20a-e, 22f-j, 23a-

e, 23f-j, elemental analyses of compounds 6a-e and 7a-l, biological assays.

Molecular modeling studies of compounds $\mathbf{6 d}$ and $\mathbf{7 d}$ 
Molecular Modeling. A series of molecular modeling simulations were performed to investigate possible binding conformation for these new series of compounds. Compounds $\mathbf{6 d}$ and 7d were docked in the colchicine binding site of tubulin (PDB entry: $1 \mathrm{SA} 0)^{1}$ using MOE 2006.08 (MOE). ${ }^{2}$ To validate our docking protocol, we performed an initial run on DAMAcolchicine, the ligand co-crystallised with the protein, and MOE was able to position DAMAcolchicine in a very similar fashion to the crystallized conformation (RMSD 1.1 $\AA$ ). We then docked compounds $\mathbf{6 d}$ and $\mathbf{7 d}$, obtaining two substantially different binding modes (Figure 1) for the two compounds. In both cases, the trimethoxyphenyl group overlaps well with the corresponding colchicinoid A ring, but the benzothiophene moiety is placed in two very distinct pockets within the active site. In the case of $\mathbf{7 d}$, this group lies on the edge of the colchicine binding site, pointing towards the GTP bound to $\alpha$-tubulin. This result is in accordance with the observation that compound $\mathbf{7 d}$ is not as effective as compound $\mathbf{6} \mathbf{d}$ as an inhibitor of colchicine binding to tubulin. It is also important to notice that the amino group of 7d does not appear to have any contact with the protein, consistent with the antiproliferative activity observed with the dimethyl-substituted compound $\mathbf{7 k}$. Furthermore, the docking results obtained for $\mathbf{7 d}$ also correlate well with the experimental data obtained with the different methyl-substituted benzothiophene analogues $\mathbf{7 b - e}$, showing that positions 4, 5 and 7 of the heterocycle are more sterically hindered than position 6.

In the case of compound $\mathbf{6 d}$, the docked conformation overlaps well with the colchicine analogue in the crystallized protein complex. Moreover, although in this case, too, the amino group does not establish any direct interaction with the protein, after energy minimization of the protein/ligand complex, the ligand amino nitrogen atom is just $3.5 \AA$ from the side chain of Ser178 (residue numbering is as in the PDB for the crystal structure used ${ }^{1}$ ) (Figure 2). 
Therefore, considering that the docking protocol does not take into account protein flexibility, the formation of an hydrogen bond could be possible between the 2-amino group of compound $\mathbf{6 d}$ and the hydroxyl group of Ser178, a residue that could also be involved in the binding of colchicine, as previously reported. ${ }^{3}$ 


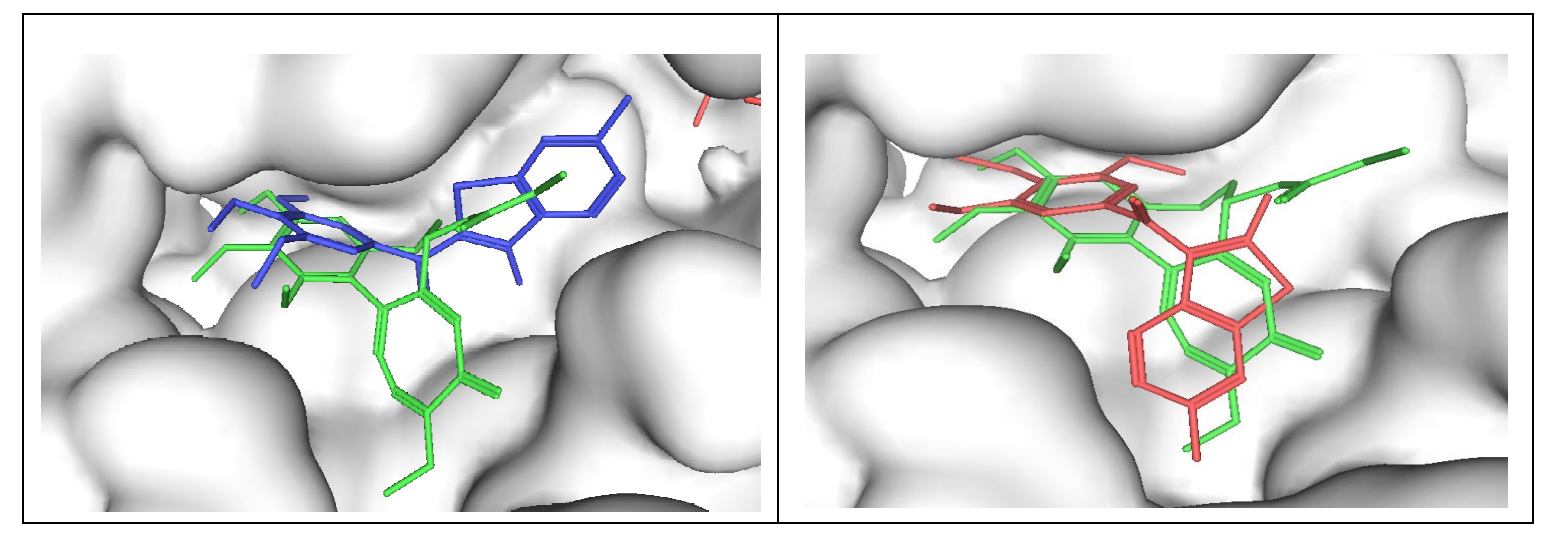

Figure 2: Proposed binding mode for compound 7d (in blue) and $6 \mathbf{d}$ (in red). DAMAcolchicine is represented in green. 


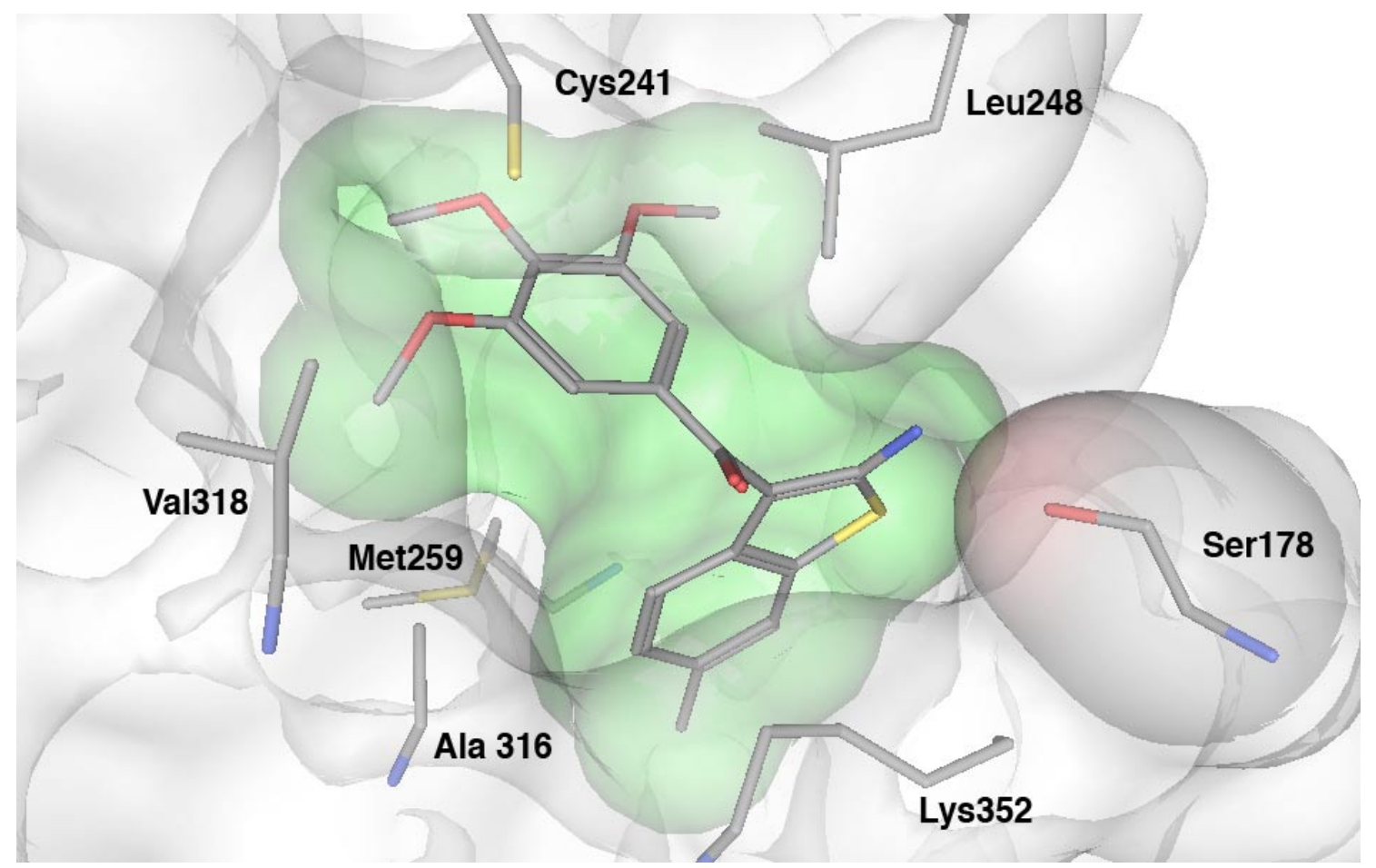

Figure 3: Binding of 6d after energy minimization. Residue numbering based on that described with the crystal structure used in the modelling studies. 


\section{Experimental Section}

Chemistry. Materials and Methods. Cyclohexanone, 4-methylcyclohexanone, 2nitrobenzonitrile, 4-methoxybenzoylacetonitrile, 2-methyl-6-nitrobenzonitrile and 4-methyl6-nitrobenzonitrile are commercially available and were used as received. For the synthesis of 13 see Seneci, P.; Nicola, M.; Inglesi, M.; Vanotti, E.; Resnati, G. Synthesis of mono- and disubstituted 1H-imidazo[1,2-b] pyrazoles. Synth. Commun. 1999, 2, 311-341; compound 14 was synthesized following Baba, A.; Mori, A.; Yasuma, T.; Unno, S., Makino, H.; Sohda, T. Studies on disease-modifying antirheumatic drugs. IV. Synthesis of novel thieno[2,3-b:5,4c']dipyridine derivatives and their anti-inflammatory effect. Chem. Pharm. Bull. 1999, 47, 993-999. 4-Methoxycyclohexanone was synthesized following Kaiho, T.; Sannohe, K.; Kajiya, S.; Suzuki, T.; Otsuka, K.; Ito, T.; Kamiya, J.; Maruyama, M. Cardiotonic agents. 1Methyl-7-(4-pyridyl)-5,6,7,8-tetrahydro-3(2H)-isoquinolinones and related compounds. Synthesis and activity. J. Med. Chem. 1989, 32, 351-357. 2-Bromo-1-(3,4,5-trimethoxyphenyl)-ethanone was synthesized following the procedure: Horton, W. J.; Thompson, G. Seven-membered ring compounds. VII. 7-Acetamidobenzosuberone and $\alpha$-amino- $\gamma-3,4,5-$ trimethoxyphenylbutyric acid. J. Am. Chem. Soc. 1954, 76, 1909-1911. 19c was synthesized following Werbel, L. M.; Elslager, E. F.; Newton, L. S. Antimalarial agents. Part 62. Synthesis and antimalarial activity of a series of 2,4-diamino-6-[(Nalkylanilino)methyl]quinazolines. J. Heterocycl. Chem. 1987, 24, 345-349; 19e was synthesized following Musso, H.; Schroeder, H. Mechanism of the oxygen transfer in the hydrogenation of 2-nitrobenzonitrile to 2-aminobenzamide. Chem. Ber. 1965, 98, 1562-1576. The intermediates 21f-j were synthesized following 21f: Klaubert, D.H.; Sellstedt, J.H.;

Guinosso, C.J.; Capetola, R.J.; Stanley, C. N-(Aminophenyl)oxamic acids and esters as 
potent, orally active antiallergy agents. J. Med. Chem. 1981, 24, 742-748; 21g: Tabarrini, O.; Cecchetti, V.; Temperini, A.; Filipponi, E.; Lamperti, M. G.; Fravolini, A.. Velnacrine thiaanalogues as potential agents for treating Alzheimer's disease. Bioorg. Med. Chem. 2001, 9, 2921-2928; 21h and 21j: Bolli, M. H.; Marfurt, J.; Grisostomi, C.; Boss, C.; Binkert, C.; Hess, P.; Treiber, A.; Thorin, E.; Morrison, K.; Buchmann, S.; Bur, D.; Ramuz, H.; Clozel, M.; Fischli, W.; Weller, T.. Novel benzo[1,4]diazepin-2-one derivatives as endothelin receptor antagonists. J. Med. Chem. 2004, 47, 2776-2795; 21i: Goto, K.; Nakamura, S.; Morioka, Y.; Kondo, M.; Naito, S.; Tsutsumi, K.. Synthesis and biological activity of the metabolites of diethyl 4-[(4-bromo-2-cyanophenyl)carbamoyl]benzylphosphonate (NO1886). Chem. Pharm. Bull. 1996, 44, 547-551.

1H NMR spectra were recorded on a Bruker AC 200 spectrometer. Chemical shifts $(\delta)$ are given in ppm upfield from tetramethylsilane as internal standard, and the spectra were recorded in appropriate deuterated solvents, as indicated. Melting points (mp) were determined on a Buchi-Tottoli apparatus and are uncorrected. All products reported showed ${ }^{1} \mathrm{H}$ NMR spectra in agreement with the assigned structures. Elemental analyses were conducted by the Microanalytical Laboratory of the Chemistry Department of the University of Ferrara. All reactions were carried out under an inert atmosphere of dry nitrogen, unless otherwise described. Standard syringe techniques were applied for transferring dry solvents. Reaction courses and product mixtures were routinely monitored by TLC on silica gel (precoated F254 Merck plates) and visualized with aqueous $\mathrm{KMnO}_{4}$. Flash chromatography was performed using 230-400 mesh silica gel and the indicated solvent system. Organic solutions were dried over anhydrous $\mathrm{Na}_{2} \mathrm{SO}_{4}$. Calcium chloride was used in the distillation of DMF, and the distilled solvent was stored over molecular sieves ( $3 \AA$ ). 


\section{(2-Amino-4,5,6,7-tetrahydrobenzo[b]thiophen-3-yl)-(3,4,5-trimethoxyphenyl)-}

methanone (9a). The crude residue was purified by flash chromatography using ethyl acetate: petroleum ether 3:7 (v:v) as eluent and furnished the compound 9a as a yellow oil (83\% yield). ${ }^{1} \mathrm{H}-\mathrm{NMR}\left(\mathrm{CDCl}_{3}\right) \delta: 1.52(\mathrm{~m}, 2 \mathrm{H}), 1.72(\mathrm{~m}, 2 \mathrm{H}), 1.95(\mathrm{t}, J=6.2 \mathrm{~Hz}, 2 \mathrm{H}), 2.53(\mathrm{t}$, $J=6.2 \mathrm{~Hz}, 2 \mathrm{H}), 3.86(\mathrm{~s}, 3 \mathrm{H}), 3.88(\mathrm{~s}, 6 \mathrm{H}), 6.54(\mathrm{bs}, 2 \mathrm{H}), 6.74$ (s, 2H).

\section{(2-Amino-4,5,6,7-tetrahydrobenzo[b]thiophen-3-yl)-(3,4-dimethoxyphenyl)-methanone}

(9b). The crude residue was purified by flash chromatography using ethyl acetate:petroleum ether 3:7 (v:v) as eluent and furnished $9 \mathrm{~b}$ as a yellow solid $\left(67 \%\right.$ yield), mp $160-161{ }^{\circ} \mathrm{C} .{ }^{1} \mathrm{H}-$ $\operatorname{NMR}\left(\mathrm{CDCl}_{3}\right) \delta: 1.52(\mathrm{~m}, 2 \mathrm{H}), 1.72(\mathrm{~m}, 2 \mathrm{H}), 1.95(\mathrm{~m}, 2 \mathrm{H}), 2.53(\mathrm{~m}, 2 \mathrm{H}), 3.92(\mathrm{~s}, 3 \mathrm{H}), 3.94$ (s, 3H), $6.30(\mathrm{bs}, 2 \mathrm{H}), 6.86(\mathrm{~d}, J=9.0 \mathrm{~Hz}, 1 \mathrm{H}), 7.14(\mathrm{~d}, J=2.0 \mathrm{~Hz}, 1 \mathrm{H}), 7.15(\mathrm{dd}, J=9.0$ and $2.0 \mathrm{~Hz}, 1 \mathrm{H})$.

\section{(2-Amino-4,5,6,7-tetrahydro-benzo[b]thiophen-3-yl)-(4-methoxy-phenyl)-methanone}

(9c). The crude residue was purified by flash chromatography using ethyl acetate: petroleum ether 2:8 (v:v) as eluent and furnished the compound 9c as a yellow solid (65\% yield), mp 120-122 ${ }^{\circ} \mathrm{C} .{ }^{1} \mathrm{H}-\mathrm{NMR}\left(\mathrm{CDCl}_{3}\right): \delta 1.5(\mathrm{~m}, 2 \mathrm{H}), 1.7(\mathrm{~m}, 2 \mathrm{H}), 1.9(\mathrm{t}, J=6.2 \mathrm{~Hz}, 2 \mathrm{H}), 2.5(\mathrm{t}$, $J=6.4 \mathrm{~Hz}, 2 \mathrm{H}), 3.8(\mathrm{~s}, 3 \mathrm{H}), 6.3(\mathrm{bs}, 2 \mathrm{H}), 6.8(\mathrm{~d}, J=8.8 \mathrm{~Hz}, 2 \mathrm{H}), 7.5(\mathrm{~d}, J=8.4 \mathrm{~Hz}, 2 \mathrm{H})$.

\section{(2-Amino-6-methyl-4,5,6,7-tetrahydrobenzo[b]thiophen-3-yl)-(3,4,5-trimethoxyphenyl)-}

methanone (9d). The crude residue was purified by flash chromatography using ethyl acetate:petroleum ether 3:7 (v:v) as eluent and furnished 9d as a yellow solid (64\% yield), mp 73-75 ${ }^{\circ} \mathrm{C} .{ }^{1} \mathrm{H}-\mathrm{NMR}\left(\mathrm{CDCl}_{3}\right): \delta 1.01(\mathrm{~d}, J=6.6 \mathrm{~Hz}, 3 \mathrm{H}), 1.16(\mathrm{~m}, 1 \mathrm{H}), 1.74(\mathrm{~m}, 2 \mathrm{H}), 1.97(\mathrm{~m}$, 2H), $2.84(\mathrm{~m}, 2 \mathrm{H}), 3.86(\mathrm{~s}, 3 \mathrm{H}), 3.89$ (s, 6H), $6.52(\mathrm{bs}, 2 \mathrm{H}), 6.74(\mathrm{~s}, 2 \mathrm{H})$. 


\section{(2-Amino-6-methoxy-4,5,6,7-tetrahydrobenzo[b]thiophen-3-yl)-(3,4,5-}

trimethoxyphenyl)-methanone (9e). The crude residue was purified by flash chromatography using ethyl acetate:petroleum ether 4:6 (v:v) as eluent and furnished 9e as a yellow solid (64\% yield), mp 111-113 ${ }^{\circ} \mathrm{C} .{ }^{1} \mathrm{H}-\mathrm{NMR}\left(\mathrm{CDCl}_{3}\right): \delta 1.68(\mathrm{~m}, 2 \mathrm{H}), 2.01(\mathrm{~m}, 2 \mathrm{H})$, $2.63(\mathrm{~m}, 1 \mathrm{H}), 2.82(\mathrm{~m}, 1 \mathrm{H}), 3.36(\mathrm{~s}, 3 \mathrm{H}), 3.63(\mathrm{~m}, 1 \mathrm{H}), 3.86(\mathrm{~s}, 6 \mathrm{H}), 3.88(\mathrm{~s}, 3 \mathrm{H}), 6.62(\mathrm{bs}$, 2H), $6.74(\mathrm{~s}, 2 \mathrm{H})$.

\section{$N$-[3-(3,4,5-trimethoxybenzoyl)-4,5,6,7-tetrahydrobenzo[b]thiophen-2-yl]-acetamide}

(10a). The crude residue was purified by flash chromatography using ethyl acetate:petroleum ether 2:8 (v:v) as eluent and furnished 10a as a yellow solid $\left(56 \%\right.$ yield), mp $178-180{ }^{\circ} \mathrm{C} .{ }^{1} \mathrm{H}-$ NMR $\left(\mathrm{CDCl}_{3}\right): \delta 1.55(\mathrm{~m}, 2 \mathrm{H}), 1.78(\mathrm{~m}, 2 \mathrm{H}), 2.07(\mathrm{t}, J=6.2 \mathrm{~Hz}, 2 \mathrm{H}), 2.24(\mathrm{~s}, 3 \mathrm{H}), 2.68(\mathrm{t}$, $J=6.2 \mathrm{~Hz}, 2 \mathrm{H}), 3.87(\mathrm{~m}, 3 \mathrm{H}), 3.92(\mathrm{~m}, 6 \mathrm{H}), 6.81(\mathrm{bs}, 2 \mathrm{H}), 11.1(\mathrm{bs}, 1 \mathrm{H})$.

\section{$N$-[3-(3,4-dimethoxybenzoyl)-4,5,6,7-tetrahydrobenzo[b]thiophen-2-yl]-acetamide (10b).}

The crude residue was purified by flash chromatography using ethyl acetate:petroleum ether 2:8 (v:v) as eluent and furnished $\mathbf{1 0 b}$ as a yellow solid (53\% yield), mp 134-136 ${ }^{\circ} \mathrm{C} .{ }^{1} \mathrm{H}-\mathrm{NMR}$ $\left(\mathrm{CDCl}_{3}\right): \delta 1.55(\mathrm{~m}, 2 \mathrm{H}), 1.78(\mathrm{~m}, 2 \mathrm{H}), 2.07(\mathrm{t}, J=6.0 \mathrm{~Hz}, 2 \mathrm{H}), 2.24(\mathrm{~s}, 3 \mathrm{H}), 2.68(\mathrm{t}, J=6.0$ Hz, 2H), 3.87 (s, 3H), 3.92 (s, 3H), 6.85 (d, J=8.8 Hz, 1H), 7.19 (d, J=1.6 Hz, 1H), 7.26 (dd, $J=8.8$ and $1.6 \mathrm{~Hz}, 1 \mathrm{H}), 11.1(\mathrm{bs}, 1 \mathrm{H})$.

$N$-[3-(4-methoxybenzoyl)-4,5,6,7-tetrahydrobenzo[b]thiophen-2-yl]-acetamide (10c). The crude residue was purified by flash chromatography using ethyl acetate:petroleum ether 1:9 (v:v) as eluent and furnished 10c as a yellow solid (65\% yield), mp 113-115 ${ }^{\circ} \mathrm{C} .{ }^{1} \mathrm{H}-\mathrm{NMR}$ $\left(\mathrm{CDCl}_{3}\right): \delta 1.6(\mathrm{~m}, 2 \mathrm{H}), 1.8(\mathrm{~m}, 2 \mathrm{H}), 2.1(\mathrm{t}, J=7.2 \mathrm{~Hz}, 2 \mathrm{H}), 2.3(\mathrm{~s}, 3 \mathrm{H}), 2.8(\mathrm{t}, J=7.2 \mathrm{~Hz}, 2 \mathrm{H})$, $3.8(\mathrm{~s}, 3 \mathrm{H}), 6.8$ (d, J=8.8 Hz, 2H), 7.8 (d, J=8.8 Hz, 2H), 11.1 (bs, 1H). 


\section{$N$-[6-methyl-3-(3,4,5-trimethoxybenzoyl)-4,5,6,7-tetrahydrobenzo[b]thiophen-2-yl]-}

acetamide (10d). The crude residue was purified by flash chromatography using ethyl acetate:petroleum ether 2:8 (v:v) as eluent and furnished 10d as a yellow oil (58\% yield). ${ }^{1} \mathrm{H}-$ NMR $\left(\mathrm{CDCl}_{3}\right): \delta 1.06(\mathrm{~d}, J=6.4 \mathrm{~Hz}, 3 \mathrm{H}), 1.17(\mathrm{~m}, 1 \mathrm{H}), 1.68(\mathrm{~m}, 2 \mathrm{H}), 2.29(\mathrm{~s}, 3 \mathrm{H}), 2.34(\mathrm{~m}$, 2H), $2.88(\mathrm{~m}, 2 \mathrm{H}), 3.86(\mathrm{~s}, 3 \mathrm{H}), 3.91(\mathrm{~s}, 6 \mathrm{H}), 7.00(\mathrm{~s}, 2 \mathrm{H}), 11.3$ (bs, 1H).

\section{$N$-[6-methoxy-3-(3,4,5-trimethoxybenzoyl)-4,5,6,7-tetrahydrobenzo[b]thiophen-2-yl]-}

acetamide (10e). The crude residue was purified by flash chromatography using ethyl acetate:petroleum ether 4:6 (v:v) as eluent and furnished 10e as a yellow oil (57\% yield). ${ }^{1} \mathrm{H}-$ NMR $\left(\mathrm{CDCl}_{3}\right): \delta 1.72(\mathrm{~m}, 4 \mathrm{H}), 2.25(\mathrm{~s}, 3 \mathrm{H}), 2.67(\mathrm{~m}, 1 \mathrm{H}), 3.02(\mathrm{~m}, 1 \mathrm{H}), 3.37(\mathrm{~s}, 3 \mathrm{H}), 3.62$ (s, 1H), 3.87 (s, 3H), $3.92(\mathrm{~s}, 6 \mathrm{H}), 6.81(\mathrm{~s}, 2 \mathrm{H}), 11.4(\mathrm{bs}, 1 \mathrm{H})$.

$N$-[3-(3,4,5-trimethoxybenzoyl)-benzo[b]thiophen-2-yl]-acetamide (11a). The crude residue was purified by flash chromatography using ethyl acetate:petroleum ether 2:8 (v:v) as eluent and furnished 11a as a yellow solid (72\% yield), mp 166-168 ${ }^{\circ} \mathrm{C} .{ }^{1} \mathrm{H}-\mathrm{NMR}\left(\mathrm{CDCl}_{3}\right)$ : $\delta$ $2.25(\mathrm{~s}, 3 \mathrm{H}), 3.79(\mathrm{~m}, 3 \mathrm{H}), 3.83(\mathrm{~m}, 6 \mathrm{H}), 6.94(\mathrm{~s}, 2 \mathrm{H}), 7.12(\mathrm{t}, J=8.4 \mathrm{~Hz}, 1 \mathrm{H}), 7.16(\mathrm{t}, J=8.8$ $\mathrm{Hz}, 1 \mathrm{H}), 7.19$ (d, J=8.4 Hz, 1H), 7.75 (t, J=8.8 Hz, 1H), 11.9 (bs, 1H).

$N$-[3-(3,4-dimethoxybenzoyl)-benzo[b]thiophen-2-yl]-acetamide (11b). The crude residue was purified by flash chromatography using ethyl acetate:petroleum ether 2:8 (v:v) as eluent and furnished $\mathbf{1 1 b}$ as a yellow solid $\left(73 \%\right.$ yield), mp 147-149 ${ }^{\circ} \mathrm{C} .{ }^{1} \mathrm{H}-\mathrm{NMR}\left(\mathrm{CDCl}_{3}\right): \delta 2.35$ (s, 3H), 3.87 (s, 3H), 3.99 (s, 3H), 6.90 (s, J=8.4 Hz, 1H), 7.16-7.37 (m, 5H), 7.75 (t, J=8.8 $\mathrm{Hz}, 1 \mathrm{H}), 11.9$ (bs, 1H).

$N$-[3-(4-methoxybenzoyl)-benzo[b]thiophen-2-yl]-acetamide (11c). The crude residue purified by flash chromatography using ethyl acetate:petroleum ether 1:9 (v:v) as eluent and 
furnished 11c as a yellow solid $\left(61 \%\right.$ yield), mp 165-167 ${ }^{\circ} \mathrm{C} .{ }^{1} \mathrm{H}-\mathrm{NMR}\left(\mathrm{CDCl}_{3}\right): \delta 2.34(\mathrm{~s}$, 3H), $3.90(\mathrm{~s}, 3 \mathrm{H}), 6.96(\mathrm{t}, 1 \mathrm{H}), 7.12(\mathrm{~m}, 1 \mathrm{H}), 7.13(\mathrm{t}, 1 \mathrm{H}), 7.15(\mathrm{~m}, 1 \mathrm{H}), 7.70(\mathrm{~d}, J=8.8 \mathrm{~Hz}$, 2H), $7.75(\mathrm{~d}, J=8 \mathrm{~Hz}, 2 \mathrm{H}), 11.8(\mathrm{bs}, 1 \mathrm{H})$.

$N$-[6-methyl-3-(3,4,5-trimethoxybenzoyl)-benzo[b]thiophen-2-yl]-acetamide (11d). The crude residue was purified by flash chromatography using ethyl acetate:petroleum ether 2:8 (v:v) as eluent and furnished 11d as a yellow solid (62\% yield), mp 81-83 ${ }^{\circ} \mathrm{C} .{ }^{1} \mathrm{H}-\mathrm{NMR}$ $\left(\mathrm{CDCl}_{3}\right): \delta 2.34(\mathrm{~s}, 3 \mathrm{H}), 3.90(\mathrm{~s}, 3 \mathrm{H}), 6.96(\mathrm{t}, 1 \mathrm{H}), 7.12(\mathrm{~m}, 1 \mathrm{H}), 7.13(\mathrm{t}, 1 \mathrm{H}), 7.15(\mathrm{~m}, 1 \mathrm{H})$, $7.70(\mathrm{~d}, J=8.8 \mathrm{~Hz}, 2 \mathrm{H}), 7.75(\mathrm{~d}, J=8.8 \mathrm{~Hz}, 2 \mathrm{H}), 11.8(\mathrm{bs}, 1 \mathrm{H})$.

$N$-[6-methoxy-3-(3,4,5-trimethoxybenzoyl)-benzo[b]thiophen-2-yl]-acetamide (11e). The crude residue was purified by flash chromatography using ethyl acetate:petroleum ether 3:7 (v:v) as eluent and furnished 11e as a yellow solid (51\% yield), mp 142-144 ${ }^{\circ} \mathrm{C} .{ }^{1} \mathrm{H}-\mathrm{NMR}$ $\left(\mathrm{CDCl}_{3}\right): \delta 2.34(\mathrm{~s}, 3 \mathrm{H}), 3.79(\mathrm{~m}, 6 \mathrm{H}), 3.84(\mathrm{~m}, 3 \mathrm{H}), 3.95(\mathrm{~s}, 3 \mathrm{H}), 6.80(\mathrm{~d}, J=9.2 \mathrm{~Hz}, 1 \mathrm{H})$, 6.92(s, 2H), 6.99 (d, J=9.2 Hz, 1H), 7.22 (s, 1H), 11.8 (bs, 1H).

(2-Amino-benzo[b]thiophen-3-yl)-(3,4,5-trimethoxyphenyl)-methanone (6a). The crude residue was purified by flash chromatography using ethyl acetate:petroleum ether 3:7 (v:v) as eluent and furnished $\mathbf{6 a}$ as a yellow solid (63\% yield), mp 110-112 ${ }^{\circ} \mathrm{C} .{ }^{1} \mathrm{H}-\mathrm{NMR}\left(\mathrm{CDCl}_{3}\right): \delta$ $3.80(\mathrm{~s}, 3 \mathrm{H}), 3.86(\mathrm{~s}, 6 \mathrm{H}), 6.84(\mathrm{~s}, 2 \mathrm{H}), 6.86(\mathrm{bs}, 2 \mathrm{H}), 7.01$ (t, J=8.4 Hz, 1H), 7.04 (t, J=8.8 $\mathrm{Hz}, 1 \mathrm{H}), 7.06$ (d, J=8.4 Hz, 1H), 7.47 (t, J=8.8 Hz, 1H). Anal. $\left(\mathrm{C}_{18} \mathrm{H}_{17} \mathrm{NO}_{4} \mathrm{~S}\right): \mathrm{C}, \mathrm{H}, \mathrm{N}$.

(2-Amino-benzo[b]thiophen-3-yl)-(3,4-dimethoxyphenyl)-methanone (6b). The crude residue was purified by flash chromatography using ethyl acetate:petroleum ether 2:8 (v:v) as eluent and furnished $\mathbf{6 b}$ as a yellow solid (89\% yield), mp 121-123 ${ }^{\circ} \mathrm{C} .{ }^{1} \mathrm{H}-\mathrm{NMR}\left(\mathrm{CDCl}_{3}\right): \delta$ 
$3.86(\mathrm{~s}, 3 \mathrm{H}), 3.97(\mathrm{~s}, 3 \mathrm{H}), 6.90(\mathrm{~m}, 1 \mathrm{H}), 7.12(\mathrm{~m}, 1 \mathrm{H}), 7.16$ (t, $J=8.8 \mathrm{~Hz}, 1 \mathrm{H}), 7.19$ (d, J=8.4

$\mathrm{Hz}, 1 \mathrm{H}), 7.26(\mathrm{~m}, 2 \mathrm{H}), 7.75(\mathrm{t}, J=8.8 \mathrm{~Hz}, 1 \mathrm{H}), 6.53(\mathrm{bs}, 2 \mathrm{H})$. Anal. $\left(\mathrm{C}_{17} \mathrm{H}_{15} \mathrm{NO}_{3} \mathrm{~S}\right): \mathrm{C}, \mathrm{H}, \mathrm{N}$.

(2-Amino-benzo[b]thiophen-3-yl)-(4-methoxyphenyl)-methanone (6c). The crude residue was purified by flash chromatography using ethyl acetate:petroleum ether 3:7 (v:v) as eluent and furnished $\mathbf{6 c}$ as a yellow solid (56\% yield), mp 177-179 ${ }^{\circ} \mathrm{C} .{ }^{1} \mathrm{H}-\mathrm{NMR}\left(\mathrm{CDCl}_{3}\right): \delta 3.88(\mathrm{~s}$, 3H), $6.89(\mathrm{~d}, J=7.6 \mathrm{~Hz}, 1 \mathrm{H}), 6.93(\mathrm{~m}, 2 \mathrm{H}), 6.96(\mathrm{bs}, 2 \mathrm{H}), 7.0(\mathrm{~m}, 2 \mathrm{H}), 7.5(\mathrm{~d}, J=2 \mathrm{~Hz}, 1 \mathrm{H})$, 7.6 (d, J=8 Hz, 2H). Anal. $\left(\mathrm{C}_{16} \mathrm{H}_{13} \mathrm{NO}_{2} \mathrm{~S}\right): \mathrm{C}, \mathrm{H}, \mathrm{N}$.

(2-Amino-6-methylbenzo[b]thiophen-3-yl)-(3,4,5-trimethoxyphenyl)-methanone

$(6 \mathbf{d})$.

The crude residue was purified by flash chromatography using ethyl acetate:petroleum ether 3:7 (v:v) as eluent and furnished $\mathbf{6 d}$ as a yellow solid (56\% yield), mp 150-152 ${ }^{\circ} \mathrm{C} .{ }^{1} \mathrm{H}-\mathrm{NMR}$ $\left(\mathrm{CDCl}_{3}\right): \delta 2.33(\mathrm{~s}, 3 \mathrm{H}), 3.81(\mathrm{~s}, 6 \mathrm{H}), 3.93(\mathrm{~s}, 3 \mathrm{H}), 6.75(\mathrm{~d}, J=8.8 \mathrm{~Hz}, 1 \mathrm{H}), 6.83(\mathrm{~d}, J=8.8 \mathrm{~Hz}$, 1H), $6.88(\mathrm{~s}, 2 \mathrm{H}), 7.21(\mathrm{bs}, 2 \mathrm{H}), 7.33(\mathrm{~s}, 1 \mathrm{H})$. Anal. $\left(\mathrm{C}_{19} \mathrm{H}_{19} \mathrm{NO}_{4} \mathrm{~S}\right): \mathrm{C}, \mathrm{H}, \mathrm{N}$.

(2-Amino-6-methoxybenzo[b]thiophen-3-yl)-(3,4,5-trimethoxyphenyl)-methanone (6e). The crude residue was purified by flash chromatography using ethyl acetate:petroleum ether 3:7 (v:v) as eluent and furnished 6e as a yellow solid (57\% yield), mp 50-52 ${ }^{\circ} \mathrm{C} .{ }^{1} \mathrm{H}-\mathrm{NMR}$ $\left(\mathrm{CDCl}_{3}\right): \delta 3.78(\mathrm{~s}, 3 \mathrm{H}), 3.80(\mathrm{~s}, 6 \mathrm{H}), 3.92(\mathrm{~s}, 3 \mathrm{H}), 6.62(\mathrm{~d}, J=9 \mathrm{~Hz}, 1 \mathrm{H}), 6.74(\mathrm{~d}, J=9.0 \mathrm{~Hz}$, 1H), 6.85 (s, 2H), 7.02 (s, 1H), 7.20 (bs, 2H). Anal. $\left(\mathrm{C}_{19} \mathrm{H}_{19} \mathrm{NO}_{5} \mathrm{~S}\right)$ : C, H, N.

General procedure $\mathbf{E}$ for synthesis of 2-benzylthioarylnitriles (20a-e). To a cold solution (ice bath) containing o-nitroarylnitriles 19a-e $(20 \mathrm{mmol})$ and benzylmercaptan $(2.48 \mathrm{~g} ., 20$ $\mathrm{mmol})$ in $20 \mathrm{~mL}$ of DMF was added dropwise a solution of $\mathrm{KOH}(2 \mathrm{~g} ., 36 \mathrm{mmol})$ in $5 \mathrm{~mL}$ of water. The mixture was stirred at $4{ }^{\circ} \mathrm{C}$ for $2 \mathrm{~h}$ and then poured into ice water. The solid was 
collected, washed with cold water $(50 \mathrm{~mL})$, dried in vacuo over $\mathrm{P}_{2} \mathrm{O}_{5}$ and recrystallised from petroleum ether.

2-Benzylsulfanyl-6-methylbenzonitrile (20b). Following general procedure E, compound 20b was obtained as a yellow solid, yield 70\%; mp 93-95 ${ }^{\circ} \mathrm{C} .{ }^{1} \mathrm{H}-\mathrm{NMR}\left(\mathrm{CDCl}_{3}\right) \delta: 2.51$ (s, 3H), 4.19 (s, 2H), 7.10 (d, J=8.0 Hz, 1H), 7.14 (d, J=8.0 Hz, 1H), 7.28 (m, 6H).

2-Benzylsulfanyl-5-methylbenzonitrile (20c). Following general procedure E, compound 20c was obtained as a yellow solid, yield 57\%; mp 133-135 ${ }^{\circ} \mathrm{C} .{ }^{1} \mathrm{H}-\mathrm{NMR}\left(\mathrm{CDCl}_{3}\right)$ $\delta: 2.32$ (s, $3 \mathrm{H}), 4.16(\mathrm{~s}, 2 \mathrm{H}), 7.24(\mathrm{~m}, 7 \mathrm{H}), 7.42(\mathrm{~s}, 1 \mathrm{H})$.

2-Benzylsulfanyl-4-methylbenzonitrile (20d). Following general procedure E, compound 20d was obtained as a yellow solid, yield 72\%; mp 88-90 ${ }^{\circ} \mathrm{C} .{ }^{1} \mathrm{H}-\mathrm{NMR}\left(\mathrm{CDCl}_{3}\right) \delta: 2.33$ (s, 3H), 4.20 (s, 2H), 7.05 (d, J=7.6 Hz, 1H), $7.16(\mathrm{~s}, 1 \mathrm{H}), 7.28(\mathrm{~m}, 5 \mathrm{H}), 7.49$ (d, J=8.0 Hz, 1H).

2-Benzylsulfanyl-3-methylbenzonitrile (20e). Following general procedure E, compound 20e was obtained as a brown solid, yield $89 \%$; mp 101-103 ${ }^{\circ} \mathrm{C} .{ }^{1} \mathrm{H}-\mathrm{NMR}\left(\mathrm{CDCl}_{3}\right)$ $\delta: 2.28$ (s, 3H), 4.07 (s, 2H), $7.10(\mathrm{~m}, 2 \mathrm{H}), 7.20(\mathrm{~m}, 4 \mathrm{H}), 7.35(\mathrm{t}, J=8.0 \mathrm{~Hz}, 1 \mathrm{H}), 7.49$ (d, J=8.0 Hz, 1H).

General procedure $F$ for synthesis of $O$-ethyl esters of $S$-(2-cyanoaryl) dithiocarbonic acids (22f-j). A solution of $\mathrm{NaNO}_{2}(0.604 \mathrm{~g}$., $8.75 \mathrm{mmol})$ in water $(2 \mathrm{~mL})$ was added dropwise over $5 \mathrm{~min}$, with stirring, to a cold $\left(0^{\circ} \mathrm{C}\right)$ solution of compound $\mathbf{2 1 f}-\mathbf{j}(8 \mathrm{mmol})$ in $\mathrm{MeOH}(4 \mathrm{~mL})$, water $(2.4 \mathrm{~mL}), \mathrm{AcOH}(0.8 \mathrm{~mL})$ and $37 \%$ aqueous $\mathrm{HCl}$. The resulting mixture was stirred at $0{ }^{\circ} \mathrm{C}$ for an additional $10 \mathrm{~min}$, at which time the cold solution was added to a solution of potassium ethyl xanthate $(2.45 \mathrm{~g}$., $15.3 \mathrm{mmol})$ in water $(7 \mathrm{~mL})$ maintained at 65 ${ }^{\circ} \mathrm{C}$. After the mixture was stirred for $15 \mathrm{~min}$, the reaction was cooled to $25^{\circ} \mathrm{C}$. The resulting mixture was extract with EtOAc $(3 \times 15 \mathrm{~mL})$, and the combined organic extracted were 
washed with brine, dried and concentrated in vacuo. Purification by silica gel flash column chromatography (EtOAc-petroleum ether) afforded the products $\mathbf{2 2 f}-\mathbf{j}$.

$O$-Ethyl ester of 2-cyano-3-methoxyphenyl dithiocarbonic acid (22f). Following general procedure F, compound $22 \mathbf{f}$ was purified by flash column chromatography (elution with $20 \%$ EtOAc in petroleum ether). Yellow oil, yield 63\%. ${ }^{1} \mathrm{H}-\mathrm{NMR}\left(\mathrm{CDCl}_{3}\right) \delta: 1.36(\mathrm{t}, J=7.2 \mathrm{~Hz}$, 3H), $3.90(\mathrm{~s}, 3 \mathrm{H}), 4.64(\mathrm{t}, J=7.2 \mathrm{~Hz}, 2 \mathrm{H}), 7.12(\mathrm{~m}, 1 \mathrm{H}), 7.36(\mathrm{~d}, J=8.2 \mathrm{~Hz}, 1 \mathrm{H}), 7.52(\mathrm{~d}$, $J=8.2 \mathrm{~Hz}, 1 \mathrm{H})$.

$O$-Ethyl ester of 2-cyano-4-methoxyphenyl dithiocarbonic acid (22g). Following general procedure F, compound $\mathbf{2 2 g}$ was purified by flash column chromatography (elution with $20 \%$ EtOAc in petroleum ether). Yellow oil, yield 56\%. ${ }^{1} \mathrm{H}-\mathrm{NMR}\left(\mathrm{CDCl}_{3}\right) \delta: 1.37(\mathrm{t}, J=7.4 \mathrm{~Hz}$, 3H), 3.89 (s, 3H), $4.62(\mathrm{t}, J=7.4 \mathrm{~Hz}, 2 \mathrm{H}), 7.16(\mathrm{~d}, J=8.2 \mathrm{~Hz}, 1 \mathrm{H}), 7.29(\mathrm{~s}, 1 \mathrm{H}), 7.53$ (d, J=8.2 $\mathrm{Hz}, 1 \mathrm{H})$.

$O$-Ethyl ester of 2-cyano-5-methoxyphenyl dithiocarbonic acid (22h). Following general procedure F, compound $\mathbf{2 2 h}$ was purified by flash column chromatography (elution with $15 \%$ EtOAc in petroleum ether). Yellow oil, yield 53\%. ${ }^{1} \mathrm{H}-\mathrm{NMR}\left(\mathrm{CDCl}_{3}\right) \delta: 1.36(\mathrm{t}, J=7.2 \mathrm{~Hz}$, 3H), $3.88(\mathrm{~s}, 3 \mathrm{H}), 4.65(\mathrm{t}, J=7.2 \mathrm{~Hz}, 2 \mathrm{H}), 7.06(\mathrm{~d}, J=8.6 \mathrm{~Hz}, 1 \mathrm{H}), 7.16(\mathrm{~s}, 1 \mathrm{H}), 7.71(\mathrm{~d}, J=8.6$ $\mathrm{Hz}, 1 \mathrm{H})$.

$O$-Ethyl ester of 2-cyano-6-methoxyphenyl dithiocarbonic acid (22i). Following general procedure F, compound $\mathbf{2 2} \mathbf{i}$ was purified by flash column chromatography (elution with $20 \%$ EtOAc in petroleum ether). Yellow oil, yield 56\%. ${ }^{1} \mathrm{H}-\mathrm{NMR}\left(\mathrm{CDCl}_{3}\right) \delta: 1.33(\mathrm{t}, J=7.2 \mathrm{~Hz}$, 3H), $3.92(\mathrm{~s}, 3 \mathrm{H}), 4.67(\mathrm{t}, J=7.2 \mathrm{~Hz}, 2 \mathrm{H}), 7.24(\mathrm{~m}, 1 \mathrm{H}), 7.35(\mathrm{~d}, J=8.4 \mathrm{~Hz}, 1 \mathrm{H}), 7.54(\mathrm{~d}$, $J=8.4 \mathrm{~Hz}, 1 \mathrm{H})$. 
$O$-Ethyl ester of 2-cyano-4,5-dimethoxyphenyl dithiocarbonic acid (22j). Following general procedure F, compound $\mathbf{2 2} \mathbf{j}$ was obtained as an orange oil, yield $56 \%$. ${ }^{1} \mathrm{H}-\mathrm{NMR}$

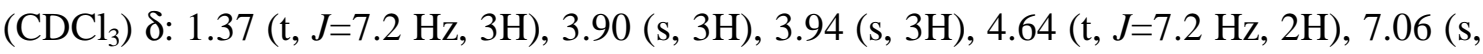
1H), $7.19(\mathrm{~s}, 1 \mathrm{H})$.

General procedure $G$ for synthesis of 2-mercaptoarylnitriles (23a-e). A solution of $S$ benzylarylnitriles 20a-e $(20 \mathrm{mmol})$ in dry benzene $(40 \mathrm{~mL})$ was added dropwise over $30 \mathrm{~min}$ to a suspension of finely powdered anhydrous aluminium chloride $(4.5 \mathrm{~g}$., $33 \mathrm{mmol})$ in dry benzene $(40 \mathrm{~mL})$, and the mixture was stirred under nitrogen at room temperature for $48 \mathrm{~h}$. The green-brown mixture was decomposed by the cautious addition of ice-water $(100 \mathrm{~mL})$, and the organic layer was separated and washed successively with water $(50 \mathrm{~mL})$ and $5 \%$ aqueous sodium hydroxide $(2 \times 50 \mathrm{~mL})$. The alkaline extracts were acidified and extracted with dichloromethane $(3 \times 50 \mathrm{~mL})$. The organic extracts were washed with brine, dried and evaporated to yield the final products 23a-e.

2-Mercapto-6-methylbenzonitrile (23b). Following general procedure G, compound 23b was obtained as a yellow solid, yield 65\%; mp 77-79 ${ }^{\circ} \mathrm{C} .{ }^{1} \mathrm{H}-\mathrm{NMR}\left(\mathrm{DMSO}-d_{6}\right) \delta: 2.52$ (s, 3H), $4.06(\mathrm{~s}, 1 \mathrm{H}), 7.04(\mathrm{~d}, J=7.2 \mathrm{~Hz}, 1 \mathrm{H}), 7.22(\mathrm{~d}, J=7.2 \mathrm{~Hz}, 1 \mathrm{H}), 7.30(\mathrm{~m}, 1 \mathrm{H})$.

2-Mercapto-5-methylbenzonitrile (23c). Following general procedure G, compound 23c was obtained as a yellow solid, yield 67\%; mp 45-47 ${ }^{\circ} \mathrm{C} .{ }^{1} \mathrm{H}-\mathrm{NMR}\left(\mathrm{DMSO}-d_{6}\right) \delta: 2.32$ (s, 3H), 3.97 (s, 1H), 7.23 (d, J=8.4 Hz, 1H), 7.33 (d, J=8.4 Hz, 1H), 7.41 (s, 1H).

2-Mercapto-4-methylbenzonitrile (23d). Following general procedure G, compound 23d was obtained as a yellow solid, yield 68\%; mp 38-40 ${ }^{\circ} \mathrm{C} .{ }^{1} \mathrm{H}-\mathrm{NMR}$ (DMSO- $d_{6}$ ) $\delta: 2.36$ (s, 3H), $4.02(\mathrm{~s}, 1 \mathrm{H}), 7.00(\mathrm{~d}, J=8.8 \mathrm{~Hz}, 1 \mathrm{H}), 7.22(\mathrm{~s}, 1 \mathrm{H}), 7.49$ (d, J=8.0 Hz, 1H). 
2-Mercapto-3-methylbenzonitrile (23e). Following general procedure G, compound 23e was obtained as a yellow solid, yield 74\%; mp 50-51 ${ }^{\circ} \mathrm{C} .{ }^{1} \mathrm{H}-\mathrm{NMR}\left(\mathrm{CDCl}_{3}\right) \delta: 2.36(\mathrm{~s}, 3 \mathrm{H})$, $4.19(\mathrm{~s}, 1 \mathrm{H}), 7.15$ (t, $J=7.8 \mathrm{~Hz}, 1 \mathrm{H}), 7.32(\mathrm{~d}, J=7.8 \mathrm{~Hz}, 1 \mathrm{H}), 7.49$ (d, J=7.8 Hz, 1H).

General procedure $\mathbf{H}$ for the synthesis of 2-mercaptoarylnitriles (23f-j). Xanthate $22 \mathrm{f}-\mathbf{j}$ ( $3 \mathrm{mmol})$ was dissolved in $\mathrm{EtOH}(10 \mathrm{~mL})$. A $3 \mathrm{~N}$ aqueous solution of $\mathrm{NaOH}(12 \mathrm{~mL})$ was added, and the reaction mixture was heated to $65^{\circ} \mathrm{C}$ for $2 \mathrm{~h}$. The reaction mixture was cooled to $25{ }^{\circ} \mathrm{C}$ and acidified to $\mathrm{pH} 5$ by the addition of $10 \%$ aqueous $\mathrm{HCl}$. The resulting mixture was extracted with EtOAc (3 x $15 \mathrm{~mL})$, and the combined organic extracts were washed with brine, dried over $\mathrm{Na}_{2} \mathrm{SO}_{4}$ and concentrated in vacuo to furnish the corresponding 2mercaptoarylnitrile $\mathbf{2 3 f}-\mathbf{j}$, which was used without further purification for the next reaction.

2-Mercapto-6-methoxybenzonitrile (23f). Following general procedure H, compound $23 f$ was obtained as a yellow solid, yield 64\%; m.p. $72-74{ }^{\circ} \mathrm{C} .{ }^{1} \mathrm{H} \mathrm{NMR}\left(\mathrm{CDCl}_{3}\right) \delta: 3.88(\mathrm{~s}, 3 \mathrm{H})$, $4.20(\mathrm{~s}, 1 \mathrm{H}), 7.21(\mathrm{~d}, J=8.4 \mathrm{~Hz}, 1 \mathrm{H}), 7.36(\mathrm{~d}, J=8.4 \mathrm{~Hz}, 1 \mathrm{H}), 7.62(\mathrm{~d}, J=8.4 \mathrm{~Hz}, 1 \mathrm{H})$.

2-Mercapto-5-methoxybenzonitrile (23g). Following general procedure H, compound 23g was obtained as a yellow oil, yield 63\%. ${ }^{1} \mathrm{H}-\mathrm{NMR}\left(\mathrm{DMSO}-d_{6}\right) \delta: 3.86(\mathrm{~s}, 3 \mathrm{H}), 4.02(\mathrm{~s}, 1 \mathrm{H})$, $7.34(\mathrm{~d}, J=8.6 \mathrm{~Hz}, 1 \mathrm{H}), 7.42(\mathrm{~d}, J=8.6 \mathrm{~Hz}, 1 \mathrm{H}), 7.52$ (s, 1H).

2-Mercapto-4-methoxybenzonitrile (23h). Following general procedure H, compound 23 h was obtained as a yellow oil, yield 72\%. ${ }^{1} \mathrm{H}-\mathrm{NMR}\left(\mathrm{DMSO}-d_{6}\right) \delta: 3.84(\mathrm{~s}, 3 \mathrm{H}), 4.04(\mathrm{~s}, 1 \mathrm{H})$, $7.04(\mathrm{~d}, J=9.0 \mathrm{~Hz}, 1 \mathrm{H}), 7.42(\mathrm{~s}, 1 \mathrm{H}), 7.56(\mathrm{~d}, J=9.0 \mathrm{~Hz}, 1 \mathrm{H})$.

2-Mercapto-3-methoxybenzonitrile (23i). Following general procedure H, compound 23i was obtained as a yellow solid, yield 57\%; mp 44-46 ${ }^{\circ} \mathrm{C} .{ }^{1} \mathrm{H}-\mathrm{NMR}\left(\mathrm{CDCl}_{3}\right) \delta: 3.90(\mathrm{~s}, 3 \mathrm{H})$, 4.22 (s, 1H), 7.17 (d, J=8.6 Hz, 1H), 7.30 (d, J=8.6 Hz, 1H), 7.49 (d, J=8.6 Hz, 1H). 
2-Mercapto-4,5-dimethoxybenzonitrile (23j). Following general procedure $\mathrm{H}$, compound 23j was obtained as a yellow solid, yield $68 \%$, mp 53-55 ${ }^{\circ} \mathrm{C} .{ }^{1} \mathrm{H}-\mathrm{NMR}$ (DMSO- $d_{6}$ ) $\delta: 3.88$ (s, 3H), $3.93(\mathrm{~s}, 3 \mathrm{H}), 4.02(\mathrm{~s}, 1 \mathrm{H}), 7.10(\mathrm{~s}, 1 \mathrm{H}), 7.22(\mathrm{~s}, 1 \mathrm{H})$.

\section{General procedure I for the synthesis of 2-(3',4',5'-trimethoxybenzoyl)-3-amino} benzo[b]thiophenes $(\mathbf{7 a - j})$. To a solution of $23 \mathbf{a}-\mathbf{j}(1 \mathrm{mmol})$ in dry acetone $(15 \mathrm{~mL})$ was added 2-bromo-1-(3,4,5-trimethoxyphenyl)-ethanone (289 $\mathrm{mg}, 1 \mathrm{mmol})$ and anhydrous potassium carbonate $(276 \mathrm{mg}, 2 \mathrm{mmol}$ ) while stirring, and the reaction mixture was refluxed for $18 \mathrm{~h}$. After cooling, the solvent was evaporated, and the residue was dissolved in a mixture of dichloromethane $(15 \mathrm{~mL})$ and water $(5 \mathrm{~mL})$. The organic layer was washed with brine, dried and evaporated to obtain a residue, which was purified by flash column chromatography. The final product was precipitated from petroleum ether.

2-(3,4,5-Trimethoxybenzoyl)-3-aminobenzo[b]thiophene (7a). The crude residue purified by flash chromatography using ethyl acetate:petroleum ether 3:7 (v:v) as eluent furnished 7a

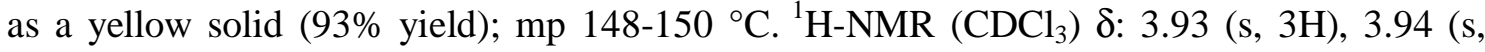
6H), 7.02 (bs, 2H), $7.21(\mathrm{~s}, 2 \mathrm{H}), 7.42(\mathrm{~d}, J=7.6 \mathrm{~Hz}, 1 \mathrm{H}), 7.51$ (d, J=7.2 Hz, 1H), 7.76 (dd, $J=7.2$ and $7.6 \mathrm{~Hz}, 2 \mathrm{H})$. Anal. $\left(\mathrm{C}_{18} \mathrm{H}_{17} \mathrm{NO}_{4} \mathrm{~S}\right): \mathrm{C}, \mathrm{H}, \mathrm{N}$.

2-(3,4,5-Trimethoxybenzoyl)-3-amino-4-methylbenzo[b]thiophene (7b). The crude residue purified by flash chromatography using ethyl acetate:petroleum ether 3:7 (v:v) as eluent furnished $\mathbf{7 b}$ as a yellow solid (90\% yield); mp 197-199 ${ }^{\circ} \mathrm{C} .{ }^{1} \mathrm{H}-\mathrm{NMR}\left(\mathrm{CDCl}_{3}\right) \delta: 2.87$ (s, 3H), $3.92(\mathrm{~s}, 3 \mathrm{H}), 3.93(\mathrm{~s}, 6 \mathrm{H}), 6.88(\mathrm{bs}, 2 \mathrm{H}), 7.10(\mathrm{~d}, \mathrm{~J}=8.0 \mathrm{~Hz}, 1 \mathrm{H}), 7.16(\mathrm{~s}, 2 \mathrm{H}), 7.34$ (t, $J=7.0 \mathrm{~Hz}, 1 \mathrm{H}), 7.53(\mathrm{~d}, J=8.0 \mathrm{~Hz}, 1 \mathrm{H})$. Anal. $\left(\mathrm{C}_{19} \mathrm{H}_{19} \mathrm{NO}_{4} \mathrm{~S}\right): \mathrm{C}, \mathrm{H}, \mathrm{N}$. 
2-(3,4,5-Trimethoxybenzoyl)-3-amino-5-methylbenzo[b]thiophene (7c). The crude residue purified by flash chromatography using ethyl acetate:petroleum ether 3:7 (v:v) as eluent furnished 7c as a yellow solid (54\% yield); mp 148-150 ${ }^{\circ} \mathrm{C} .{ }^{1} \mathrm{H}-\mathrm{NMR}\left(\mathrm{CDCl}_{3}\right) \delta: 2.44(\mathrm{~s}$, 3H), 3.89 (s, 3H), 3.91 (s, 6H), 7.07 (bs, 2H), 7.19 (s, 2H), 7.16 (d, J=8.2 Hz, 1H), 7.51 (s, 1H), 7.59 (d, J=8.2 Hz, 1H). Anal. $\left(\mathrm{C}_{19} \mathrm{H}_{19} \mathrm{NO}_{4} \mathrm{~S}\right): \mathrm{C}, \mathrm{H}, \mathrm{N}$.

2-(3,4,5-Trimethoxybenzoyl)-3-amino-6-methylbenzo[b]thiophene (7d). The crude residue purified by flash chromatography using ethyl acetate:petroleum ether $3: 7$ (v:v) as eluent furnished $\mathbf{7 d}$ as a yellow solid (78\% yield); mp 128-130 ${ }^{\circ} \mathrm{C} .{ }^{1} \mathrm{H}-\mathrm{NMR}\left(\mathrm{CDCl}_{3}\right) \delta: 2.49$ (s, 3H), $3.93(\mathrm{~s}, 3 \mathrm{H}), 3.94(\mathrm{~s}, 6 \mathrm{H}), 7.01(\mathrm{bs}, 2 \mathrm{H}), 7.20(\mathrm{~s}, 2 \mathrm{H}), 7.22(\mathrm{~d}, J=8.0 \mathrm{~Hz}, 1 \mathrm{H}), 7.51$ (s, $1 \mathrm{H}), 7.62(\mathrm{~d}, J=8.0 \mathrm{~Hz}, 1 \mathrm{H})$. Anal. $\left(\mathrm{C}_{19} \mathrm{H}_{19} \mathrm{NO}_{4} \mathrm{~S}\right): \mathrm{C}, \mathrm{H}, \mathrm{N}$.

2-(3,4,5-Trimethoxybenzoyl)-3-amino-7-methylbenzo[b]thiophene (7e). The crude residue purified by flash chromatography using ethyl acetate:petroleum ether $3: 7(\mathrm{v}: \mathrm{v})$ as eluent

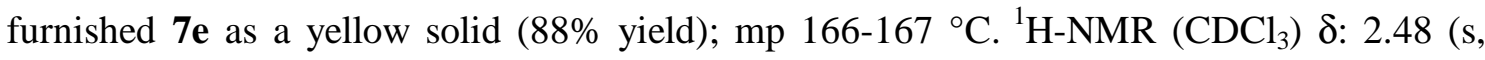
3H), $3.92(\mathrm{~s}, 3 \mathrm{H}), 3.94(\mathrm{~s}, 6 \mathrm{H}), 7.02(\mathrm{bs}, 2 \mathrm{H}), 7.21(\mathrm{~s}, 2 \mathrm{H}), 7.32$ (d, J=7.8 Hz, 1H), 7.36 (t, $J=7.8 \mathrm{~Hz}, 1 \mathrm{H}), 7.64(\mathrm{~d}, J=7.8 \mathrm{~Hz}, 1 \mathrm{H})$. Anal. $\left(\mathrm{C}_{19} \mathrm{H}_{19} \mathrm{NO}_{4} \mathrm{~S}\right): \mathrm{C}, \mathrm{H}, \mathrm{N}$.

2-(3,4,5-Trimethoxybenzoyl)-3-amino-4-methoxybenzo[b]thiophene (7f). The crude residue purified by flash chromatography using ethyl acetate:petroleum ether 4:6 (v:v) as eluent furnished 7f as a yellow solid (58\% yield); mp 163-165 ${ }^{\circ} \mathrm{C} .{ }^{1} \mathrm{H}-\mathrm{NMR}\left(\mathrm{CDCl}_{3}\right) \delta: 3.88$ $(\mathrm{s}, 3 \mathrm{H}), 3.94(\mathrm{~s}, 6 \mathrm{H}), 3.98(\mathrm{~s}, 3 \mathrm{H}), 7.02(\mathrm{~m}, 3 \mathrm{H}), 7.220(\mathrm{~s}, 2 \mathrm{H}), 7.40(\mathrm{~m}, 2 \mathrm{H})$. Anal. $\left(\mathrm{C}_{19} \mathrm{H}_{19} \mathrm{NO}_{5} \mathrm{~S}\right): \mathrm{C}, \mathrm{H}, \mathrm{N}$.

2-(3,4,5-Trimethoxybenzoyl)-3-amino-5-methoxybenzo[b]thiophene $\quad(7 \mathrm{~g})$. The crude residue purified by flash chromatography using ethyl acetate:petroleum ether 4:6 (v:v) as 
eluent furnished $\mathbf{7 g}$ as a yellow solid (54\% yield); mp 142-144 ${ }^{\circ} \mathrm{C} .{ }^{1} \mathrm{H}-\mathrm{NMR}\left(\mathrm{CDCl}_{3}\right) \delta$ : 3.91 (s, 3H), 3.92 (s, 6H), 3.94 (s, 3H), 6.88 (bs, 2H), 7.11 (d, J=8.8 Hz, 1H), 7.20 (s, 2H), 7.26 (s, 1H), $7.59(\mathrm{~d}, J=8.8 \mathrm{~Hz}, 1 \mathrm{H})$. Anal. $\left(\mathrm{C}_{19} \mathrm{H}_{19} \mathrm{NO}_{5} \mathrm{~S}\right): \mathrm{C}, \mathrm{H}, \mathrm{N}$.

2-(3,4,5-Trimethoxybenzoyl)-3-amino-6-methoxybenzo[b]thiophene (7h). The crude residue purified by flash chromatography using ethyl acetate:petroleum ether 4:6 (v:v) as eluent furnished $7 \mathbf{h}$ as a yellow solid (64\% yield); mp 82-84 ${ }^{\circ} \mathrm{C} .{ }^{1} \mathrm{H}-\mathrm{NMR}\left(\mathrm{CDCl}_{3}\right) \delta: 3.86(\mathrm{~s}$, 3H), $3.88(\mathrm{~s}, 3 \mathrm{H}), 3.91(\mathrm{~s}, 6 \mathrm{H}), 6.98(\mathrm{~d}, J=9.0 \mathrm{~Hz}, 1 \mathrm{H}), 7.07(\mathrm{bs}, 2 \mathrm{H}), 7.10(\mathrm{~s}, 1 \mathrm{H}), 7.17$ (s, 2H), $7.61(\mathrm{~d}, J=9.0 \mathrm{~Hz}, 1 \mathrm{H})$. Anal. $\left(\mathrm{C}_{19} \mathrm{H}_{19} \mathrm{NO}_{5} \mathrm{~S}\right): \mathrm{C}, \mathrm{H}, \mathrm{N}$.

2-(3,4,5-Trimethoxybenzoyl)-3-amino-7-methoxybenzo[b]thiophene (7i). The crude residue purified by flash chromatography using ethyl acetate:petroleum ether 4:6 (v:v) as eluent furnished 7i as a yellow solid (63\% yield); mp 152-154 ${ }^{\circ} \mathrm{C} .{ }^{1} \mathrm{H}-\mathrm{NMR}\left(\mathrm{CDCl}_{3}\right) \delta: 3.92$ $(\mathrm{s}, 3 \mathrm{H}), 3.93(\mathrm{~s}, 6 \mathrm{H}), 3.98(\mathrm{~s}, 3 \mathrm{H}), 7.00(\mathrm{~m}, 3 \mathrm{H}), 7.20(\mathrm{~s}, 2 \mathrm{H}), 7.37(\mathrm{~m}, 2 \mathrm{H})$. Anal. $\left(\mathrm{C}_{19} \mathrm{H}_{19} \mathrm{NO}_{5} \mathrm{~S}\right): \mathrm{C}, \mathrm{H}, \mathrm{N}$.

2-(3,4,5-Trimethoxybenzoyl)-3-amino-5,6-dimethoxybenzo[b]thiophene (7j). The crude residue purified by flash chromatography using ethyl acetate:petroleum ether 6:4 (v:v) as

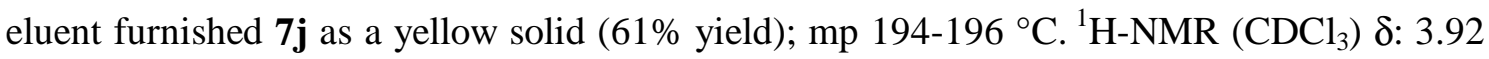
(s, 3H), 3.93 (s, 6H), 3.97 (s, 3H), 3.98 (s, 3H), 6.96 (bs, 2H), 7.04 (s, 1H), 7.10 (s, 1H), 7.19 (s, 2H). Anal. $\left(\mathrm{C}_{20} \mathrm{H}_{21} \mathrm{NO}_{6} \mathrm{~S}\right): \mathrm{C}, \mathrm{H}, \mathrm{N}$.

\section{Synthesis of 2-(3,4,5-trimethoxybenzoyl)-3-dimethylamino-6-methylbenzo[b]thiophene}

(7k). Sodium hydride (60\% oil dispersion, $48 \mathrm{mg}, 1 \mathrm{mmol})$ was carefully added to an icecooled solution of $\mathrm{CH}_{3} \mathrm{I}(62 \mu \mathrm{L}, 1 \mathrm{mmol})$ and $7 \mathbf{d}(100 \mathrm{mg}, 0.28 \mathrm{mmol})$ in $1 \mathrm{~mL}$ of DMF. The reaction vessel was sealed, and the mixture was stirred at $40{ }^{\circ} \mathrm{C}$ for $72 \mathrm{~h}$, after which time it 
was diluted with cold water $(1 \mathrm{~mL})$ and extracted with $\mathrm{CH}_{2} \mathrm{Cl}_{2}(3 \times 5 \mathrm{~mL})$. The combined organic extracts were washed with water $(2 \mathrm{~mL})$ and brine, dried and concentrated in vacuo. The resulting residue, purified by flash chromatography using ethyl acetate:petroleum ether 2:8 (v:v), provided $7 \mathbf{k}$ as an orange powder $\left(88 \%\right.$ yield), mp 107-108 ${ }^{\circ} \mathrm{C} .{ }^{1} \mathrm{H}-\mathrm{NMR}\left(\mathrm{CDCl}_{3}\right)$

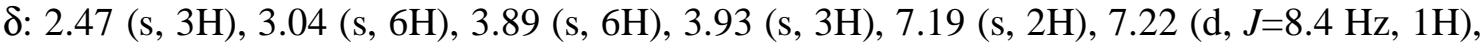
$7.51(\mathrm{~s}, 1 \mathrm{H}), 7.87(\mathrm{~d}, J=8.4 \mathrm{~Hz}, 1 \mathrm{H})$. Anal. $\left(\mathrm{C}_{21} \mathrm{H}_{23} \mathrm{NO}_{4} \mathrm{~S}\right): \mathrm{C}, \mathrm{H}, \mathrm{N}$.

\section{Synthesis of 2-(3,4,5-trimethoxybenzoyl)-3-diacetylamino-6-methylbenzo[b]thiophene}

(7l). A solution of 7d $(1 \mathrm{mmol})$ in $3 \mathrm{~mL}$ of pyridine and $2.5 \mathrm{~mL}$ of $\mathrm{Ac}_{2} \mathrm{O}$ was heated under reflux for $1 \mathrm{~h}$. Excess reagents were removed in vacuo. The residue was triturated with water $(3 \mathrm{~mL})$ and extracted with dichloromethane $(3 \times 5 \mathrm{~mL})$. The combined organic extracts were washed with brine $(5 \mathrm{~mL})$, dried, filtered and evaporated. Flash chromatography on silica gel, eluting with $30 \%$ EtOAc in petroleum ether, gave $7 \mathbf{l}$ as a yellow powder, yield $84 \%$, mp 151-

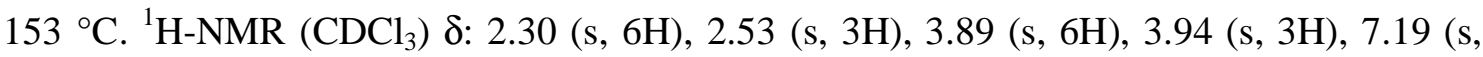
2H), $7.32(\mathrm{~d}, J=8.0 \mathrm{~Hz}, 1 \mathrm{H}), 7.52(\mathrm{~d}, J=8.0 \mathrm{~Hz}, 1 \mathrm{H}), 7.69$ (s, 1H). Anal. $\left(\mathrm{C}_{23} \mathrm{H}_{23} \mathrm{NO}_{6} \mathrm{~S}\right): \mathrm{C}, \mathrm{H}$, N.

Cell growth inhibitory activity. Murine leukemia L1210, murine mammary carcinoma FM3A and human T-lymphocyte Molt 4 and CEM cells were suspended at 300,000-500,000 cells/mL of culture medium, and $100 \mu \mathrm{L}$ of a cell suspension was added to $100 \mu \mathrm{L}$ of an appropriate dilution of the test compounds in wells of 96-well microtiter plates. After incubation at $37{ }^{\circ} \mathrm{C}$ for two (L1210 and FM3A) or three (Molt 4 and CEM) days, cell number was determined using a Coulter counter. The $\mathrm{IC}_{50}$ was defined as the compound concentration required to inhibit cell proliferation by $50 \%$. 
Effects on tubulin polymerization and on colchicine binding to tubulin. Bovine brain tubulin was purified as described previously. ${ }^{4}$ To evaluate the effect of the compounds on tubulin assembly in vitro, ${ }^{5}$ varying concentrations were preincubated with $10 \mu \mathrm{M}$ tubulin in glutamate buffer at $30{ }^{\circ} \mathrm{C}$ and then cooled to $0{ }^{\circ} \mathrm{C}$. After addition of GTP, the mixtures were transferred to $0{ }^{\circ} \mathrm{C}$ cuvettes in a recording spectrophotometer and warmed to $30{ }^{\circ} \mathrm{C}$, and the assembly of tubulin was observed turbidimetrically. The $\mathrm{IC}_{50}$ was defined as the compound concentration that inhibited the extent of assembly by $50 \%$ after a 20 min incubation. The ability of the test compounds to inhibit colchicine binding to tubulin was measured as described, ${ }^{6}$ except that the reaction mixtures contained $1 \mu \mathrm{M}$ tubulin, $5 \mu \mathrm{M}\left[{ }^{3} \mathrm{H}\right]$ colchicine and $1 \mu \mathrm{M}$ test compound.

Flow cytometric analysis of cell cycle distribution. The effects of the most active compounds of the series on cell cycle distribution were studied on K562 cells (myeloblastic leukemia) by flow cytometric analysis after staining with propidium iodide. Cells were exposed $24 \mathrm{~h}$ to each compound used at a concentration corresponding to the $\mathrm{IC}_{50}$ determined after a $24 \mathrm{~h}$ incubation. After treatment, the cells were washed once in ice-cold PBS and resuspended at $1 \times 10^{6}$ per $\mathrm{mL}$ in a hypotonic fluorochrome solution containing propidium iodide (Sigma) at $50 \mu \mathrm{g} / \mathrm{mL}$ in $0.1 \%$ sodium citrate plus $0.03 \%$ (v/v) nonidet P-40 (Sigma). After a 30 min incubation, the fluorescence of each sample was analyzed as single-parameter frequency histograms by using a FACScan flow cytometer (Becton Dickinson, San Jose, CA). The distribution of cells in the cell cycle was analyzed with the ModFit LT3 program (Verity Software House, Inc.).

Molecular Modeling. All molecular modeling studies were performed on a RM Innovator with Pentium IV $3 \mathrm{GHz}$ processor, running Linux Fedora Core 4 using Molecular Operating 
Environment (MOE) 2006.08. ${ }^{2}$ The tubulin structure was downloaded from the PDB data bank (http://www.rcsb.org/ - PDB code: $1 \mathrm{SA} 0) .{ }^{1}$ Hydrogen atoms were added to the protein with MOE and minimized keeping all the heavy atoms fixed until a RMSD gradient of 0.05 $\mathrm{kcal} \mathrm{mol}^{-1} \AA^{-1}$ was reached. Ligand structures were built with MOE and minimized using the MMFF94x forcefield until a RMSD gradient of $0.05 \mathrm{kcal} \mathrm{mol}^{-1} \AA^{-1}$ was reached. The docking simulations were performed using the Alpha Triangle placement method and the London dG scoring method. 300 results for each ligand were generated, and the position of the trimethoxyphenyl moiety was compared with ring A of the colchicine analogue cocrystallized with the protein, discarding the results with a RMSD value $>3 \AA^{7}$ The best scored result of the remaining conformations for each ligand was then further analyzed. The protein/ligand complexes were minimized using the MMFF94x force field, until a RMSD gradient of $0.1 \mathrm{kcal} \mathrm{mol}^{-1} \AA^{-1}$ was reached.

\section{References}

(1). Ravelli, R. B. G.; Gigant, B.; Curmi, P. A.; Jourdain, I.; Lachkar, S.; Sobel, A.; Knossow, M. Insight into tubulin regulation from a complex with colchicine and a stathmin-like domain. Nature 2004, 428, 198-202.

(2). Molecular Operating Environment (MOE 2006.08). Chemical Computing Group, Inc. Montreal, Quebec, Canada. http://www.chemcomp.com.

(3). De Martino, G.; Edler, M. C.; La Regina, G.; Coluccia, A.; Barbera, M. C.; Barrow, D.; Nicholson, R. I.; Chiosis, G.; Brancale, A.; Hamel, E.; Artico, M.; Silvestri, R. Arythioindoles, potent inhibitors of tubulin polymerization. 2. Structure activity relationships and molecular modeling studies. J. Med. Chem. 2006, 49, 947-954. 
(4) Hamel, E.; Lin, C.M. Separation of active tubulin and microtubule-associated proteins by ultracentrifugation and isolation of a component causing the formation of microtubule bundles. Biochemistry 1984, 23, 4173-4184.

(5) Hamel, E. Evaluation of antimitotic agents by quantitative comparisons of their effects on the polymerization of purified tubulin. Cell Biochem. Biophys. 2003, 38, 121.

(6) Verdier-Pinard, P.; Lai J.-Y.; Yoo, H.-D.; Yu, J.; Marquez, B.; Nagle D.G.; Nambu, M.; White, J.D.; Falck, J.R.; Gerwick, W.H.; Day, B.W.; Hamel, E. Structure-activity analysis of the interaction of curacin A, the potent colchicine site antimitotic agent, with tubulin and effects of analogs on the growth of MCF-7 breast cancer cells. Mol. Pharmacol. 1998, 53, 62-67.

(7). Code "fragment_rmsd.svl” obtained from SLV Exchange website http://svl.chemcomp.com., Chemical Computing Group, Inc. Montreal, Canada

\section{SUPPLEMENTARY}

Elemental analyses of derivatives 6a-e and 7a-l.

\begin{tabular}{ccccccccc}
\hline compd & formula & MW & \multicolumn{3}{c}{ Calcd } & \multicolumn{3}{c}{ Found } \\
& & & \% $\mathbf{C}$ & \% $\mathbf{H}$ & \% $\mathbf{~}$ & \% $\mathbf{C}$ & \% $\mathbf{~}$ & \% N \\
\hline 6a & $\mathrm{C}_{18} \mathrm{H}_{17} \mathrm{NO}_{4} \mathrm{~S}$ & 343.40 & 62.96 & 4.99 & 4.08 & 62.78 & 4.74 & 3.97 \\
$\mathbf{6 b}$ & $\mathrm{C}_{17} \mathrm{H}_{15} \mathrm{NO}_{3} \mathrm{~S}$ & 313.37 & 65.16 & 4.82 & 4.47 & 65.03 & 4.67 & 4.25
\end{tabular}




\begin{tabular}{ccccccccc}
$\mathbf{6 c}$ & $\mathrm{C}_{16} \mathrm{H}_{13} \mathrm{NO}_{2} \mathrm{~S}$ & 283.34 & 67.82 & 6.62 & 4.94 & 67.58 & 6.48 & 4.76 \\
$\mathbf{6 d}$ & $\mathrm{C}_{19} \mathrm{H}_{19} \mathrm{NO}_{4} \mathrm{~S}$ & 357.42 & 63.85 & 5.36 & 3.92 & 63.77 & 5.27 & 3.78 \\
$\mathbf{6 e}$ & $\mathrm{C}_{19} \mathrm{H}_{19} \mathrm{NO}_{5} \mathrm{~S}$ & 373.42 & 61.11 & 5.13 & 3.75 & 60.92 & 5.02 & 3.58 \\
$\mathbf{7 a}$ & $\mathrm{C}_{18} \mathrm{H}_{17} \mathrm{NO}_{4} \mathrm{~S}$ & 343.40 & 62.96 & 4.99 & 4.08 & 62.88 & 4.78 & 3.99 \\
$\mathbf{7 b}$ & $\mathrm{C}_{19} \mathrm{H}_{19} \mathrm{NO}_{4} \mathrm{~S}$ & 357.42 & 63.85 & 5.36 & 3.92 & 63.68 & 5.17 & 3.80 \\
$\mathbf{7 c}$ & $\mathrm{C}_{19} \mathrm{H}_{19} \mathrm{NO}_{4} \mathrm{~S}$ & 357.42 & 63.85 & 5.36 & 3.92 & 63.70 & 5.22 & 3.68 \\
$\mathbf{7 d}$ & $\mathrm{C}_{19} \mathrm{H}_{19} \mathrm{NO}_{4} \mathrm{~S}$ & 357.42 & 63.85 & 5.36 & 3.92 & 63.58 & 5.17 & 3.66 \\
$\mathbf{7 e}$ & $\mathrm{C}_{19} \mathrm{H}_{19} \mathrm{NO}_{4} \mathrm{~S}$ & 357.42 & 63.85 & 5.36 & 3.92 & 63.61 & 5.19 & 3.70 \\
$\mathbf{7 f}$ & $\mathrm{C}_{19} \mathrm{H}_{19} \mathrm{NO}_{5} \mathrm{~S}$ & 373.42 & 61.11 & 5.13 & 3.75 & 60.94 & 5.01 & 3.48 \\
$\mathbf{7 g}$ & $\mathrm{C}_{19} \mathrm{H}_{19} \mathrm{NO}_{5} \mathrm{~S}$ & 373.42 & 61.11 & 5.13 & 3.75 & 61.01 & 4.89 & 3.61 \\
$\mathbf{7 h}$ & $\mathrm{C}_{19} \mathrm{H}_{19} \mathrm{NO}_{5} \mathrm{~S}$ & 373.42 & 61.11 & 5.13 & 3.75 & 60.97 & 4.99 & 3.62 \\
$\mathbf{7 i}$ & $\mathrm{C}_{19} \mathrm{H}_{19} \mathrm{NO}_{5} \mathrm{~S}$ & 373.42 & 61.11 & 5.13 & 3.75 & 60.92 & 4.86 & 3.55 \\
$\mathbf{7 j}$ & $\mathrm{C}_{20} \mathrm{H}_{21} \mathrm{NO}_{6} \mathrm{~S}$ & 403.45 & 59.54 & 5.25 & 3.47 & 59.25 & 5.11 & 3.34 \\
$\mathbf{7 k}$ & $\mathrm{C}_{21} \mathrm{H}_{23} \mathrm{NO}_{4} \mathrm{~S}$ & 385.48 & 65.43 & 6.01 & 3.63 & 65.22 & 5.85 & 3.51 \\
$\mathbf{7 1}$ & $\mathrm{C}_{23} \mathrm{H}_{23} \mathrm{NO}_{6} \mathrm{~S}$ & 441.5 & 62.57 & 5.25 & 3.17 & 62.38 & 5.02 & 3.01 \\
\hline
\end{tabular}

Table of Contents Graphic 


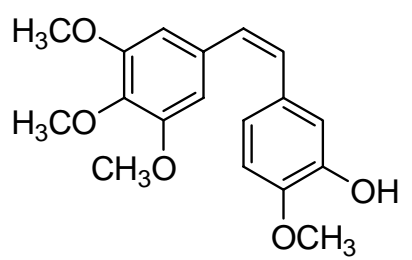

Combretastatin A-4 (CA-4)

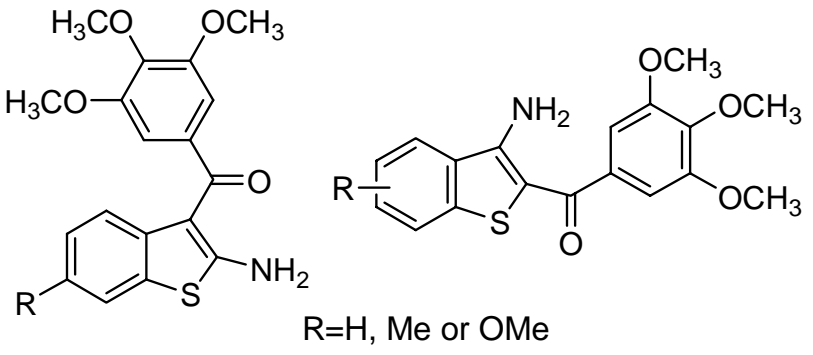

